\title{
Vivências de atendimentos ginecológicos por mulheres lésbicas e bissexuais: (in)visibilidades e barreiras para o exercício do direito à saúde
} Experiences of gynecological care by lesbian and bisexual women: (in)visibility and barriers to the exercise of the right to health

\author{
Julliana Luiz Rodrigues ${ }^{a}$ \\ (iD) https://orcid.org/0000-0003-2871-0744 \\ E-mail: jlrodriguesळunifesp.br \\ Marcia Thereza Couto Falcão ${ }^{b}$ \\ (D) https://orcid.org/0000-0001-5233-4190 \\ E-mail: marthetøusp.br \\ aniversidade Federal de São Paulo. Escola Paulista de Medicina. \\ Departamento de Medicina Preventiva. Laboratório de Saúde \\ Coletiva. São Paulo, SP, Brasil. \\ buniversidade de São Paulo. Faculdade de Medicina. Departamento \\ de Medicina Preventiva. Programa de Pós-Graduação em Saúde \\ Coletiva. São Paulo, SP, Brasil.
}

\section{Resumo}

Embora lésbicas e mulheres bissexuais tenham sido incluídas nas políticas de saúde, na busca por uma atenção integral e que inclua o reconhecimento da diversidade sexual, a discriminação persiste nos espaços de atenção à saúde, especialmente nas consultas clínicas. Este trabalho, de vertente qualitativa, teve por objetivo discutir, a partir das percepções e vivências dessas mulheres, as relações estabelecidas nas consultas ginecológicas, abordando especificamente a (não) revelação da condição de lésbica/bissexual, as experiências com exames e orientações pertinentes à sexualidade e as dificuldades de negociação de condutas. A produção dos dados empíricos deu-se por meio de entrevistas semiestruturadas com doze lésbicas e cinco mulheres bissexuais. Os resultados apontam para a invisibilidade bissexual no contexto clínico, para as dificuldades na consulta ginecológica tanto para lésbicas quanto bissexuais e para o temor das mulheres quanto à exposição da orientação sexual, bem como o não reconhecimento de sua sexualidade. Nesse sentido, as consultas em ginecologia continuam centradas em pressupostos heteronormativos, preponderando aspectos reprodutivos em detrimento dos aspectos sexuais da vida.

Palavras-chave: Lésbica; Bissexualidade; Sexualidade; Cuidado à Saúde; Pesquisa Qualitativa.

\section{Correspondência}

Julliana Luiz Rodrigues

Rua Botucatu 740, 4 andar. São Paulo, SP, Brasil. CEP 04021-00I. 


\section{Introdução}

Although lesbian and bisexual women have been included in health policies, in the search for comprehensive care, including the recognition of sexual diversity, discrimination persists in health care spaces, especially in clinical consultations. Based on the perceptions and experiences of these women, this qualitative study discusses, the relationships established in gynecological consultations, addressing the disclosure of the status of being lesbian/bisexual, experiences with exams and guidelines relevant to sexuality and the difficulties of negotiating conduct. The production of empirical data took place through semi-structured interviews with twelve lesbians and five bisexuals. The results point to bisexual invisibility in the clinical context. Difficulties in gynecological consultation involve fears regarding the exposure of sexual orientation, as well as the non-validation of their sexuality. Consultations in gynecology remain centered on heteronormative assumptions. Thus, they operate with a preponderance of reproductive aspects to the detriment of sexual aspects of life.

Keywords: Lesbian; Bisexuality; Sexuality; Comprehensive Health Care; Qualitative Research.
A visibilidade de identidades denominadas LGBT (lésbicas, gays, bissexuais, travestis e transexuais) tem provocado inquietações quanto ao tema "sexualidade", tanto em grupos ativistas como em pesquisadores de diversas áreas de conhecimento. Problematizações acerca da temática LGBT trazem à tona discussões sobre direitos sexuais e reprodutivos consagrados, até então, aos heterossexuais. Assim, a diversidade sexual e seus desdobramentos no campo médico, jurídico e social têm provocado vários questionamentos e reflexões por pesquisadores das ciências humanas e sociais e da interface destas com a saúde.

No campo acadêmico, os estudos que floresceram a partir da década de 1980 (Aquino, 1995; Guimarães, 2004; Heilborn, 2004; Parker, 1999) inauguraram o debate sobre as liberdades de orientação e expressão sexuais, marcando a passagem de abordagens centradas no indivíduo e na "etiologia" da homossexualidade para uma abordagem centrada na inter-relação sujeitosociedade e no contexto sociocultural. Alguns autores importantes, como Jeffrey Weeks (2010), Henrieta Moore (1997), Gayle Rubin (1975) e Carol Vance (1991), fomentaram discussões sobre sexualidade, compreendendo-a como um campo de atuação de forças e luta política permeada por jogos de poder, para além de uma função biológica.

Autores desconstrucionistas, como Butler (2003), não apenas tecem uma crítica à naturalização da sexualidade, mas também ao próprio conceito de gênero. Butler pensa o gênero como performance que pode se dar em qualquer corpo, portanto desconectado da ideia de que a cada corpo corresponderia somente um gênero (Butler, 2003). O corpo, então, não é mais considerado como um dado natural e não há identidades que precedam o exercício das normas de gênero; é o exercício mesmo que termina por criar as normas.

No campo da saúde no Brasil, observamos alguns avanços com a elaboração de políticas públicas, fruto de pesquisas e reivindicações de movimentos sociais voltadas às demandas LGBT ou feministas. Assim, reivindicações por reconhecimento de direitos no cenário nacional são palco de disputas desde o final 
dos anos de 1970, com a consequente incorporação de parte das demandas pelo governo federal, especificamente por meio da Política Nacional de Atenção Integral à Saúde da Mulher (Brasil, 2003) e da Política Nacional de Atenção Integral à Saúde de Lésbicas, Gays, Bissexuais, Travestis e Transexuais (Brasil, 2010), a partir dos anos 2000. Dentre os objetivos desta última política, estão incluídos a promoção da saúde integral, a exclusão da homofobia e de qualquer forma de discriminação, a inclusão de ações educativas nos serviços de saúde voltados a promoção da autoestima de pessoas LGBT, a ampliação do acesso ao tratamento qualificado de cânceres ginecológicos e a prevenção de novos casos entre lésbicas e bissexuais.

Deve-se reconhecer que os marcos das políticas mencionadas estão ancorados na linguagem dos direitos sexuais no século XXI que traz uma nova moralidade: o exercício da sexualidade ancorado na busca da realização pessoal, da felicidade, da saúde e do bem-estar, através do bom uso dos prazeres (Carrara, 2015). 0 desfrute do sexo como atividade autônoma quanto às escolhas de seus parceiros sexuais assinala "o reconhecimento das diversas orientações sexuais e a legitimidade de suas expressões" (Villela; Arilha, 2003, p. 136). Nesse sentido, colocam a heterossexualidade, bissexualidade e a homossexualidade como práticas igualmente livres.

Em levantamento bibliográfico sobre a condição de saúde de lésbicas e mulheres bissexuais, verificamos que alguns estudos são provenientes de outros países, especialmente dos Estados Unidos (Denenberg, 1995; Diamant; Schuster; Lever, 2000; Diamant et al., 200o; Aaron et al., 2001). A produção de conhecimento no Brasil em específico parece-nos ainda tímida, apesar de se observar nos últimos 15 anos esforços para problematizar a saúde de mulheres que se relacionam com mulheres (Barbosa; Facchini, 2009; Barbosa; Koyama, 2006; Melo, 2010; Moscheta; Fébole; Anzolin, 2016; Paulino; Rasera; Teixeira, 2019; Pinto, 2004; Rodrigues, 2011).

As condições de saúde de lésbicas e mulheres bissexuais também convocam importantes reflexões sobre como elas se apropriam de seus próprios corpos e sobre suas percepções acerca do risco das doenças. Considerando-se o tema central deste artigo, destacamos que a consulta ginecológica, por ser um momento extremamente delicado e lugar de exposição da intimidade, pode ser marcada por dificuldades, que vão desde a decisão de revelar ou não a homo/bissexualidade para o médico até as reações do profissional e as repercussões para o cuidado. Destaca-se que o encontro entre a pessoa que busca por atendimento e o médico é orientado por conceitos e práticas do saber biomédico. A partir do século XIX, a ginecologia, assim como outras áreas da medicina, passam a produzir um discurso científico a respeito da saúde e da doença pautado na relação de causa e efeito, com forte objetificação do paciente (Moulin, 2009).

Os relatos sobre a ida ao ginecologista nos poucos estudos que contemplam lésbicas e mulheres bissexuais reforçam fatores associados a convenções de gênero para o baixo acesso às consultas (Barbosa; Facchini, 2009). O estudo de Rodrigues (2011) também mostra que o imaginário associado a "ser cuidadosa e atenta à saúde", bem como outras características da sexualidade feminina - número pequeno de parcerias, desfrute do sexo quando há afetividade, controle da atividade sexual etc. - favorecem a vivência de experiências sexuais desprotegidas na relação homossexual feminina. Assim, valores hegemônicos de feminilidade, ao exigir da mulher contenção de sua sexualidade e envolvimentos sexuais mais esporádicos, fomentam a ideia de que relacionar-se com outra mulher é "naturalmente" mais seguro. Tais percepções encontram ressonância entre profissionais da saúde (Melo, 2010).

O contingente de mulheres lésbicas e bissexuais que se encontram excluídas dos serviços de saúde tem sido analisado a partir da hipótese de que os serviços são organizados a partir de uma lógica de presunção da heterossexualidade das usuárias, o que favorece o estabelecimento de um contexto discriminatório e de práticas preconceituosas dos profissionais (Barbosa; Facchini, 2009; Melo, 2010; Pinto, 2004; Rodrigues, 2011). Durante o acesso e uso dos serviços, os profissionais dificilmente questionam o tipo de relacionamento de suas pacientes ao assumirem que são heterossexuais, desconsiderando identidades e práticas sexuais diversas (Moscheta; Fébole; 
Anzolin, 2016; Pinto, 2004; Rodrigues, 2011). A heteronormatividade, construída na suposição de que todas as pessoas são heterossexuais, e normatizada nas práticas em saúde, contribui, deste modo, para tornar a homossexualidade socialmente invisível e de menor legitimidade (Bjorkman; Malterud, 20o9).

Sem dúvida, quando as mulheres se afastam da suposta linearidade sexo-gênero-sexualidade, tornam-se vulneráveis ao estigma e à discriminação. No cenário onde se desenrolam as relações entre as lésbicas e mulheres bissexuais e os profissionais da saúde, as contribuições teórico-conceituais sobre estigma, preconceito e discriminação são valiosas para compreendermos as dificuldades e impasses acerca do cuidado buscado pelas mulheres e oferecido pelos profissionais. A noção de estigma, trazida a partir de Goffman (1982), tem sido revisitada, buscando-se perspectivas ampliadas e profícuas para a saúde. Parker e Aggleton (2003) apontam que a valorização de certos atributos/ características, em detrimento de outras, não ocorre de maneira livre e descontextualizada; o estigma está sempre em estreita relação com as acepções culturais e os sistemas de poder, por isso compreender como são criados ou mantidos direciona o olhar sobre estruturas mais amplas de desigualdade social e processos de exclusão social.

Diante da pouca expressividade da produção científica sobre a relação entre saúde, homossexualidade e bissexualidade feminina e as desvantagens sociais relacionadas aos processos de estigma e discriminação nos serviços de saúde e, finalmente, dado o reconhecimento de que a saúde pode ser compreendida como cenário social onde os sujeitos colocam em ação valores, normas e suas performances de gênero, consideramos a atualidade e pertinência em investigar as concepções de lésbicas e mulheres bissexuais sobre as relações estabelecidas no contexto dos atendimentos clínicos em ginecologia. Portanto, o objetivo deste trabalho é discutir os sentidos e significados que emergem das vivências de lésbicas e mulheres bissexuais em atendimentos ginecológicos prévios e na relação com profissionais médicos/as. Exploraremos as dimensões da (não)revelação da condição de ser lésbica/bissexual, as percepções acerca da reação do médico diante da revelação da orientação não heterossexual, as experiências com exames e orientações pertinentes à sexualidade e as (im) possibilidades de negociar condutas.

\section{Percurso metodológico}

Os dados empíricos que apoiam a discussão apresentada neste trabalho fazem parte de uma pesquisa mais ampla de abordagem qualitativa que investiga as condições de saúde de mulheres lésbicas e bissexuais. 0 estudo foi conduzido após aprovação da Comissão de Ética da universidade a que esteve vinculado. A produção dos dados empíricos se norteou pela técnica de entrevista em profundidade, devido a sua potencialidade de captar, a partir de um roteiro flexível, os valores e os sentidos que os sujeitos atribuem a eventos de sua experiência pessoal.

Foram convidadas a participar da pesquisa, mulheres bissexuais ou lésbicas que tivessem 18 anos de idade ou mais segundo a estratégia de bola de neve. A partir de alguns contatos iniciais, algumas lésbicas que não faziam parte do círculo pessoal de uma das pesquisadoras foram convidadas; a partir destas, buscamos outras indicações. Outras participantes tiveram acesso à pesquisa a partir de convites de outras colegas que sabiam deste projeto e o difundiram em seus círculos sociais. Na condução dos convites havia a menção da orientação sexual como critério de inclusão. Foram realizadas dezessete entrevistas, cinco com mulheres bissexuais e doze com lésbicas, no período de novembro de 2016 a dezembro de 2017, após esclarecimento, leitura, verificação da compreensão e assinatura do Termo de Consentimento Livre e Esclarecido pelas participantes. As entrevistas foram conduzidas a partir de perguntas norteadoras, seguindo um roteiro temático, elaborado e testado na fase piloto da pesquisa para ser avaliado com relação à clareza e pertinência dentro dos objetivos propostos, cujos eixos foram: a trajetória da sexualidade; a vivência homoafetiva nos diferentes espaços sociais, incluindo a família; as moralidades dentro da relação afetivo-sexual; as ações de cuidado em saúde; a saúde sexual em contexto clínico 
ou de atendimento ginecológico; as situações de discriminações e preconceitos no atendimento médico e fora dele, quando houvessem; e, por fim, o que poderia ser implementado para melhorar o atendimento em saúde. Os locais de realização das entrevistas foram de escolha das próprias entrevistadas, desde que garantisse adequação em termos de privacidade e acústica para a gravação.

Todas as entrevistas foram gravadas em áudio digital de forma ininterrupta e transcritas na íntegra para posterior análise, respeitando-se expressões coloquiais, gírias e pausas. A duração média das entrevistas foi de uma hora e dez minutos. Para garantir o anonimato e a confidencialidade dos dados das participantes, utilizamos nomes fictícios. A coleta dos dados foi finalizada quando estes se mostraram suficientes para elucidar o fenômeno a que este projeto de pesquisa se propôs. Para isso, utilizamos o critério de saturação teórica (Fontanella; Ricas; Turato, 2008). 0 material obtido a partir das entrevistas se mostrou bastante rico para produzir um corpus de falas sobre percepções e experiências de cuidado à saúde de lésbicas e mulheres bissexuais, possibilitando recursos suficientes para a interpretação das categorias empíricas investigadas.

Para a análise dos dados, partimos da concepção da hermenêutica, na qual a compreensão "surge como algo produzido no diálogo e não como algo meramente reproduzido por um intérprete ao se deparar com um texto ou ação na busca de compreendê-lo/a" (Batista, 2012, p. 108, grifo da autora). Os resultados foram alcançados no processo de interpretação, feito com o objetivo de analisar os dados e discuti-los a partir de esquemas explanatórios teóricos (Strauss; Corbin, 2008). O material das transcrições foi lido minuciosamente até atingir a impregnação de seu conteúdo, a apreensão da lógica interna, de suas particularidades e, ao mesmo tempo, do conjunto. Após este processo de impregnação, foi realizada a leitura atenta e direcionada, visando a identificação dos eixos temáticos que incluíam aqueles previamente explorados no roteiro de entrevista e aqueles emergentes. Num segundo momento, foi realizada leitura horizontal dos relatos para compararmos as narrativas das participantes segundo os temas investigados. Nesta etapa, a apreensão dos achados foi cotejada com a literatura sobre o tema e os referenciais teóricos da pesquisa.

\section{Resultados e discussão}

Antes de entrarmos na discussão dos temas propostos, é importante destacar a dimensão da autoidentificação das participantes em relação à orientação sexual (Quadro 1). Cinco participantes se autorreferiram como bissexuais, no entanto, com diferenças significativas sobre como percebiam e experienciam suas sexualidades. Manuela e Any tinham atração por homens e mulheres e viam possibilidade de se envolverem emocional e sexualmente com ambos; enquanto, para Cristina, Danila e Giane, a bissexualidade se expressava pela afirmação da preferência por mulheres, especialmente para relacionamentos duradouros. Nesses casos, a referência bissexual é escolhida, uma vez que poderiam vir a ter relações sexuais casuais com homens, revelando também um modo de ser bissexual. Já Nayara, que também reconheceu possibilidade de vir a relacionar-se com homens, referiu-se como lésbica e não bissexual. A maioria das lésbicas, Luiza, Thalita, Lia, Naira, Tatiana e Karen, teve o início de suas vidas sexuais com homens. Estas, por um tempo, se entenderam como heterossexuais, até poderem, cada uma a seu tempo, entrar em contato com o desejo por mulheres e se reconhecerem lésbicas. Outras, como Magda, Keyla, Lara, Alana e Carol nunca sentiram atração por homens e "desde sempre", como elas próprias pontuaram, "sabiam” que eram lésbicas.

A autoidentificação das participantes revela a necessidade de compreensão de que a orientação sexual implica em uma complexidade de práticas, desejos e trajetórias sexuais que deve ser assumida criticamente, evitando-se recair em classificações que supõe fixidez e linearidade. A autonomeação da orientação sexual pareceu-nos ter um sentido importante para as participantes, em termos do reconhecimento de si e de pertencimento social (Costa, 1996). No entanto, as expressões lésbica e bissexual não traduzem um modo estanque de ser e podem não dar conta da dinâmica complexa da sexualidade, como nos alertou Judith Butler (2003) e estudiosos do construcionismo social (Weeks, 2010; Vance, 1991). 
Quadro I-Características das participantes

\begin{tabular}{|c|c|c|c|c|c|c|}
\hline Participante & Idade & Orientação & Condição afetiva & Cor & Escolaridade & Onde mora \\
\hline Lara & 21 & lésbica & namorando & branca & sup. incompleto & $\begin{array}{l}\text { Vila Nova } \\
\text { Cachoerinha }\end{array}$ \\
\hline Lia & 68 & lésbica & solteira & branca & sup. completo & Vila Madalena \\
\hline Giane & 30 & bissexual & união estável & negra & sup. completo & Centro \\
\hline Luiza & 28 & lésbica & solteira & negra & sup. incompleto & Vila Elídia \\
\hline Cristina & 34 & bissexual & solteira & negra & sup. incompleto & Butantã \\
\hline Carol & 20 & lésbica & solteira & branca & sup. incompleto & Brooklin \\
\hline Thalita & 20 & lésbica & namorando & branca & sup. incompleto & Vila Medeiros \\
\hline Naira & 19 & lésbica & solteira & branca & sup. incompleto & Vila Madalena \\
\hline Nayara & 19 & lésbica & namorando & branca & sup. incompleto & Butantã \\
\hline Keyla & 40 & lésbica & solteira & negra & ensino médio & Osasco \\
\hline Alana & 22 & lésbica & namorando & negra & sup completo & Saúde \\
\hline Any & 29 & bissexual & solteira & parda & ensino médio & Cambuci \\
\hline Magda & 45 & lésbica & namorando & branca & ens. fundamental & Parque Cocaia \\
\hline Karen & 26 & lésbica & namorando & branca & ensino médio & $\begin{array}{l}\text { Francisco } \\
\text { Morato }\end{array}$ \\
\hline Manuela & 31 & bissexual & solteira & branca & sup. completo & Brooklin \\
\hline Tatiana & 27 & lésbica & solteira & parda & $\begin{array}{l}\text { ens. med } \\
\text { incompleto }\end{array}$ & $\begin{array}{l}\text { Francisco } \\
\text { Morato }\end{array}$ \\
\hline Danila & 35 & bissexual & solteira & negra & sup. completo & Cidade Ademar \\
\hline
\end{tabular}

(Não) revelação da condição de ser lésbica/bissexual no atendimento ginecológico

A revelação da homo/bissexualidade para o profissional médico mostrou-se crucial, pois este era um momento chave no contexto das consultas. Assim, a decisão de falar ou não operou como um divisor de águas para o desencadeamento da relação a ser estabelecida. Importante ressaltar que se colocar como lésbica/ bissexual não se trata simplesmente de compartilhar uma informação, como idade ou data da última menstruação, frequentemente interrogados; requer que se quebre com pressupostos heteronormativos, exigindo uma exposição por parte das pacientes que não lhes garante, a priori, atendimento humanizado.
O constrangimento por partes das mulheres para revelar sobre a parceria sexual (parceira/parceiro) e as formas de lidar com este tema na consulta ginecológica não foram homogêneas e merecem ser analisadas. Orientação sexual e apropriação de feminilidades/masculinidades enquanto expressão de gênero são categorias significativas para compreendermos algumas particularidades da (não)revelação da orientação sexual em um atendimento ginecológico.

Notamos diferença entre as lésbicas e as mulheres bissexuais; as primeiras, ainda que tivessem verbalizado diversos incômodos e dificuldades, buscaram por oportunidades na interação com o médico de se afirmarem enquanto lésbicas. 
No caso das bissexuais, nenhuma delas verbalizou ou tentou verbalizar a orientação sexual. Chama a atenção a invisibilidade bissexual, não como fruto de uma escolha individual, mas atrelada a contextos de cuidado à saúde em que as práticas sexuais de mulheres só são legitimadas se forem com homens (Moscheta; Fébole; Anzolin, 2016).

O lugar social circunscrito a homens e mulheres, sustentado pela concepção binária de gênero, constitui um campo de significação a respeito dos corpos, dos comportamentos sexuais e das relações amorosas (Moscheta; Fébole; Anzolin, 2016). A aceitação de algumas formas de vida como mais aceitáveis que outras, dentre elas a heterossexualidade, pode contribuir para que mulheres bissexuais omitam a orientação sexual e exponham somente a faceta de relacionamentos com homens. Além disso, arriscamos interpretar que a invisibilidade da mulher bissexual nos espaços de cuidado à saúde reitera dificuldades enfrentadas em outros círculos sociais. Sendo reconhecidas muitas vezes como confusas ou indecisas, especialmente por não definirem apenas um objeto de desejo, elas se sentem menos autorizadas a se colocarem como bissexuais no contexto da consulta ginecológica como em outros contextos sociais. Nestes termos, vê-se a orientação sexual articulada à performance de gênero, favorecendo visibilidade apenas à parcela que atende aos padrões normativos - neste caso, envolver-se com homens. A fala de Manuela expressa essa situação:

É uma relação muito formal, é uma relação muito distante. Muito distante! Todavez, uma vezporano, elerecomenda exame porque é exame de rotina, mas ele não pergunta nada sobre minha vida.

Ele não sabe que você é uma mulher com atividade sexual com homens e mulheres?

Não, não sabe.

Você avalia que seria pertinente ele saber disso?

Deveria né, mas eu não consigo falar. Eu acho que não faz diferença, para medicina não faz a menor diferença. As perguntas que sãofeitas, a forma como é feito o atendimento, o que ele quer ver de exame clínico, não faz diferença se entra um pau na minha buceta ou se euraspo com outra periquita. (Manuela, 31 anos, bissexual, branca)

A fala de Manuela explicita a categoria de análise desenvolvida por Paulino, Rasera e Teixeira (2019), "Discursos do Não", que neste caso trata-se da "não diferença”. Esta é utilizada por médicos para minimizar a diferença entre a população LGBT e demais populações, sob o argumento de uma suposta igualdade. Contudo, um dos efeitos dessas falas é justamente o apagamento do próprio sujeito. Conforme salienta Baker e Beagan (2014) em seu estudo com 38 mulheres e 24 médicos(as), na tentativa de tratar todos igualmente, o profissional acaba por contribuir mais ainda para a lesbo/ bifobia, uma vez que a suposta neutralidade reforça concepções normativas de sexualidade e de gênero.

Todas as participantes lésbicas entendiam que era de extrema importância dar visibilidade à orientação sexual durante o atendimento, corroborando resultado semelhante encontrado por Johnson e Nemeth (2014), por Bjorkman e Malterud (2009) e por Baker e Beagan (2014) em pesquisa qualitativa com mulheres lésbicas/bissexuais norte americanas, norueguesas e canadenses, respectivamente.

Barreiras em torno da revelação da orientação sexual entre as lésbicas dizem respeito também às performances e identidade de gênero. Relatos sobre dificuldades mais expressivas de revelação sobressaltaram nas que "performam" de modo mais masculino. Segundo Barbosa e Facchini (2009), a ida ao ginecologista pode ser compreendida como uma afirmação de necessidades femininas, e, portanto, uma conduta para as mulheres lésbicas que se percebem como femininas. Para as lésbicas que possuem atributos e posturas corporais masculinizadas, a consulta adquire um significado de tornar explícito os trejeitos desviantes que, somado às representações de que os relacionamentos lésbicos não oferecem riscos nem requerem ações específicas com a saúde, tornam a busca por cuidados ginecológicos especialmente complexa e difícil. Exemplificando: Magda, lésbica com performances masculinas, recordou-se de ter ido ao ginecologista uma vez quando jovem, ocasião em que se sentiu desconfortável. Dois anos atrás, teve de 
realizar uma cirurgia de emergência para retirada do útero e, por conta desta intervenção, acumulou mais idas ao ginecologista que a soma das vezes anteriores. Ela descreveu os procedimentos e exames como extremamente desconfortáveis, ainda mais se realizados por um profissional do sexo masculino.

Tais achados salientam que o acesso e as percepções sobre as necessidades em saúde estão atreladas à orientação sexual e à maneira como a identidade de gênero é "performada". Ou seja, o cuidado em saúde sensível a mulheres lésbicas e bisexuais depende da orientação sexual e da perfomances de gênero, entendido como uma construção contínua de estilos corporais, que dão a ilusão de um eu marcado pelo gênero (Butler, 2003).

Para algumas participantes, a oportunidade de expor a orientação sexual se dava depois da pergunta sobre o uso de métodos contraceptivos, momento ímpar para desconstruir o pressuposto de que são heterossexuais:

Eu falei, porque a primeira pergunta é "o que você faz para não terneném?". "Eu transo com mulheres, é isso que faço”, digo ao médico. (Lara, 21 anos, lésbica, branca)

Eu sempre falo quando vou. "Que método anticoncepcional você usa?" "Eu transo com mulheres”, geralmente é assim que conto para os médicos. (Giane, 30 anos, bissexual, negra)

Eu falo porque a primeira coisa que eles perguntam é "você toma anticoncepcional?"(Cristina, 34 anos, bissexual, negra)

Se, por um lado, algumas participantes aproveitaram o questionamento sobre o uso de anticoncepcional como porta de entrada para se colocarem como lésbicas, por outro lado, tal pergunta reiterou pressupostos heteronormativos e dificultou a revelação sobre a diversidade de suas práticas sexuais. Além disso, a pergunta sobre anticoncepção logo no início do atendimento, na percepção de muitas entrevistadas, relaciona-se com a medicalização do corpo feminino, como se toda mulher em idade reprodutiva estivesse lidando com a contracepção. Cristina demonstrou claramente seu desagrado:
Eu acho estúpida esta pergunta, é uma pergunta burra, burra! Primeiro, porque tomar anticoncepcional é uma merda. [...] Segundo, porque não previne de doença nenhuma. $E$ terceiro, onde fica quem transa com mulheres?

A simples estratégia de fazer perguntas abertas (De Oliveira; Almeida; Nogueira, 2014) e questionamentos sobre como a sexualidade é percebida e experienciada (Baker; Beagan, 2014), sem que o sexo do parceiro fosse suposto de antemão e sem perguntas sobre o anticoncepcional logo de início, poderia propiciar a revelação da orientação sexual. No entanto, esta postura do profissional não apareceu no relato de nenhuma das participantes.

\section{A reação do profissional médico diante de uma paciente não heterossexual}

A descrição sobre a reação do médico diante da revelação da orientação homossexual ou bissexual chama a atenção pela inabilidade do profissional em lidar com a informação. Apenas duas, Magda e Keyla, não identificaram algo de negativo na reação do profissional. As demais relataram reações que incluíam desde o "ficar sem graça”, "não saber como conduzir a consulta" até "comentários preconceituosos e deslegitimação do sexo lésbico”.

Ao dar a notícia de que sou lésbica, só falta cair da cadeira. Você percebe que ele perde completamente a compostura. (Lara, 21 anos, lésbica, branca)

Eu acho super importante se colocar como lésbica e já vi de tudo... Já vi os caras ficarem perturbadinhos! É muito comum a pessoa ficar sem saber o que fazer. (Lia, 68 anos, lésbica, branca)

Para todas, independente da orientação lésbica ou bissexual, não foi incomum que recebessem tratamento pouco acolhedor e até desrespeitoso dos profissionais diante da revelação. Este dado reforça a hipótese de que há uma cultura heterossexual e lesbo/bifóbica na formação dos médicos, que se atualiza no cuidado em saúde a partir de práticas de exclusão e subjugação (Raimondi et al., 2019). Uma das consequências é a responsabilização das mulheres 
acerca da difícil decisão de revelar a orientação sexual e lidar com possível hostilidade ou permanecer invisível e se sujeitar a tratamento inadequado, o que também foi apontado por Davis (2005).

Aspectos negativos decorrentes da inabilidade do profissional foram expressos e, dentre eles, acelerar a consulta ou deixar de pedir exames estão entre os mais citados. Estes comportamentos são corroborados pela pesquisa realizada por Barbosa e Facchini (2009) na cidade de São Paulo. Ser atendida mais rápido após a revelação foi verbalizado por Karen:

Quando você chega e fala "sou lésbica", aí pode começar o preconceito, como aconteceu com ele, quando eu cheguei ele estava normal, quando eu falei, ele [médico] começou a acelerar a consulta. (Karen, 26 anos, lésbica, branca)

O desrespeito se expressou na deslegitimação das práticas sexuais com mulheres. A situação narrada por Alana é exemplar. Ela relatou que já havia tido experiência desagradável quando atendida pela ginecologista da Unidade Básica de Saúde (UBS), em Francisco Morato; pontuou que era lésbica e o médico registrou "virgem" em sua ficha. Ficou incomodada, uma vez que tinha práticas sexuais e não se reconhecia como virgem. No entanto, apesar do incômodo gerado, não conseguiu se posicionar nem assinalar o equívoco. Alana conta que não compareceu ao retorno, abandonou o tratamento e permaneceu anos sem buscar por tais cuidados.

Ao mudar-se para São Paulo, retomou os cuidados ginecológicos e, ao passar pela segunda vez, situação semelhante se desenrolou: fora nomeada “meio virgem" pela profissional, quando ela relia rapidamente as anotações do atendimento anterior e relembrou que a paciente nunca tivera relação sexual com homem. Alana sentiu-se novamente desrespeitada, uma vez que a relação sexual com mulheres não foi considerada "sexo":

Ela tratou como se fosse brincadeira, "mais ou menos virgem". "Ah, você é meio virgem, pela metade", disse a médica, tirando sarro. Eu fiquei super séria e ela não percebeu. Aí não sei se consigo passar com ela de novo. (Alana, 22 anos, lésbica, negra)
Experiência semelhante foi vivenciada por Karen, que não apresentava histórico de idas frequentes ao ginecologista. Sua última busca por atendimento havia sido impulsionada a partir de conversas com amigas, que a alertaram sobre a necessidade de realizar o exame Papanicolau. Karen estava receosa se poderia se submeter ao exame, pois havia tido uma única relação sexual com homem, anos atrás. Tinha dúvida se estava apta à coleta do Papanicolau devido à introdução de aparelho na vagina, mas foi motivada pelas amigas para expor ao médico que era lésbica e, assim, pedir esclarecimento. Mas durante o atendimento, o médico perguntou a ela se tinha vida sexual ativa, ao que respondeu:

Eu disse "tenho", e falei que era com mulher. Ele disse: "Não, quero saber com homem!" O quê?? Como assim? Eu cheguei a falar: "Vida sexual ativa é só com homem?". Ele já me olhou... Era um senhor, do jeito que ele me olhou, já entendi que sexo, para ele, é só com homem. (Karen, 26 anos, lésbica, branca)

Em ambos os casos houve a deslegitimação das relações sexuais entre mulheres, colocando o sexo com parceiros homens, e somente com parceiros homens, como a referência de atividade sexual. 0 descaso quanto às relações eróticas entre mulheres expressa o estereótipo falocêntrico que liga a atividade sexual à penetração do pênis, disseminando a equivocada ideia de que lésbicas/bissexuais não fazem sexo. As relações eróticas entre mulheres tornam-se impensáveis ou desprezíveis em uma cultura misógina, que transforma a sexualidade feminina em instrumento do desejo masculino (Borrillo, 2010).

$\mathrm{Na}$ relação de cuidado à saúde, apesar da informação oferecida pelas mulheres acerca de suas práticas sexuais, permanece acionado o saber normativo de gênero e a heterossexualidade compulsória, com o apagamento das práticas sexuais entre mulheres (Moscheta; Fébole; Anzolin, 2016). Dados semelhantes aos nossos estão também presentes na literatura internacional (Johnson; Nemeth, 2014), apontando reações preconceituosas por parte de médicos e até mesmo atitudes rudes durante a realização de exames. 
Experiências com exames e orientações pertinentes à vida sexual e (im)possibilidades de negociar condutas

Outras dificuldades que permearam a relação com médico foram a realização do exame Papanicolau e o recebimento de orientações. As participantes destacaram que as informações fornecidas pelos profissionais eram confusas e não pertinentes a elas. A consulta ginecológica, não raro, se desenrolava com o profissional fornecendo orientações pouco plausíveis e instruções inócuas, mesmo a paciente tendo exposto a orientação sexual. Dificultando a efetividade do cuidado, as participantes não se sentiram confortáveis para pedir esclarecimentos quando os termos utilizados pelo profissional não foram claros e precisos, permanecendo a sensação de um encontro desnecessário e dispensável.

Estudo já citado, realizado na Noruega, mostrou que o recebimento de informações médicas voltadas para atividades heterossexuais, a prescrição de contraceptivos e até realização de testes de gravidez, mesmo depois de revelar uma orientação lésbica de longa data, foram algumas das condutas médicas com mulheres lésbicas (Bjorkman; Malterud, 2009). Em nossos achados, como em outros estudos brasileiros, evidenciamos que mesmo que as mulheres revelassem serem lésbicas ou bissexuais, ainda assim, não era garantido o recebimento de informações pertinentes a sua sexualidade (Barbosa; Facchini, 2009; Pinto, 2004; Rodrigues, 2011), com desconsideração das falas das usuárias e dos pedidos de esclarecimentos em relação ao cuidado à saúde (Moscheta; Fébole; Anzolin, 2016).

Todas as participantes apontaram o exame de prevenção de câncer de colo de útero como indiscutivelmente desconfortável. Não obstante, nenhuma delas verbalizou recusa em realizá-lo. Para as bissexuais, ou as que já tiveram relações sexuais com homens, a realização do exame era menos aversiva, pela familiaridade que tinham (ou tiveram) com a prática da penetração. Para algumas lésbicas, que nunca tiveram relações sexuais com homens, o exame tomava contornos mais preocupantes, especialmente quanto a sua pertinência e real necessidade de concretizá-lo. Para as mulheres que apresentavam performances masculinas, a irregularidade na realização do Papanicolau foi mais acentuada, em comparação às demais lésbicas e bissexuais. Para Magda, lésbica que mantinha performance masculina, a realização do Papanicolau esbarrava em limites relacionados à identidade de gênero e à forma como vivenciava sua sexualidade. A introdução de um instrumento na vagina para mulheres cuja identificação não é com os padrões normativos de feminilidade pode adquirir sentido de grande aversão ou até violência. Verifica-se que a normatização do cuidado não inclui uma abordagem para realizar exames em mulheres que não têm práticas de penetração, culminando em exames invasivos e situações constrangedoras (Moscheta; Fébole; Anzolin, 2016).

Eu fiz [exame Papanicolau] uma vez na vida, achei absurdo, que situação horrível aquela! Fiz lá atrás, e nunca mais fiz na vida, acho que fugia de ginecologista justamente por causa desse exame, nunca gostei. Quer tirar sangue, tira, quer colocar aparelho na garganta coloca, mas não lá embaixo, não mexe, não. [...] É uma situação muito horrível, eu não me sinto confortável em fazer, então eu prefiro não fazer. Então a saúde passava... (Magda, 45 anos, lésbica, branca)

Outra dificuldade apontada foi quanto ao recebimento de informações que faziam sentido à prática sexual que mantinham. Isto se deu, entre outras razões, pelo fato dos profissionais utilizarem expressões em que não ficava elucidado a quais práticas se referiam, tampouco o sexo do parceiro. Pela equivocada assunção de que as mulheres eram heterossexuais e pela maneira como os atendimentos foram conduzidos, com preponderância dos aspectos reprodutivos, as expressões referiram-se à atividade sexual com homens.

Luiza descreveu que, quando expunha práticas sexuais com mulheres, isto não necessariamente ressoava na consulta, pois acreditava que o médico não sabia quais orientações deveriam ser passadas a uma paciente heterossexual e a uma lésbica e as similaridades e diferenças entre elas:

Ele anota lá que sou lésbica, e daí? Será que ele sabe quais as necessidades de uma mulher lésbica? Como orientar? Com os recursos que ele tem, devia trazer orientação que pudesse ajudar. Mas não énada disso que acontece. (Luiza, 28 anos, lésbica, negra) 
O “discurso do não saber” (Paulino; Rasera; Teixeira , 2019) é identificado quando os profissionais referem não saber quais são as demandas da população LGBT. Não se trata de ele ser falso ou verdadeiro, mas de uma suposta tranquilidade com que o profissional se exime de sua responsabilidade na relação de cuidado.

Ainda que haja importantes lacunas na formação médica quanto a temas de orientação sexual e de gênero, o fato de supostamente não terem conhecimento a este respeito não é justificativa em si para negligenciarem o atendimento (Paulino; Rasera; Teixeira, 2019), tampouco para desconsiderarem as singularidades dos usuários que atendem. Assim, ainda que a lógica heteronormativa esteja fortemente presente na formação médica, apropriar-se das singularidades da trajetória afetiva-sexual faz parte do compromisso ético do médico.

Corroborando com nossos achados, pesquisa sobre as condições de saúde de mulheres lésbicas e bissexuais na Argentina afirma que, de fato, três dos principais problemas de acesso à saúde de lésbicas e mulheres bissexuais estão diretamente ligados ao caráter heteronormativo da consulta: (1) a ocultação da orientação afetivo-sexual ou a gestão do segredo do homossexualidade e, consequentemente; (2) a invisibilidade das práticas homoeróticas femininas; e (3) a informação deficiente fornecida às mulheres, adicionada aos mitos e preconceitos difundidos (Brown et al., 2014). Na mesma direção, a falta de conhecimentos específicos sobre cuidado de saúde LGBT foi alarmante entre os médicos que participaram do estudo de Baker e Beagan (2014).

A (im)possibilidade de diálogo com os médicos acerca do funcionamento do corpo feminino e a negociação de condutas também foram pontos relevantes. Com relação às prescrições, a recomendação de contraceptivo oral foi frequente, mesmo diante da recusa para sua administração ou dúvidas quanto ao porquê de ter sido indicado.

A dificuldade central em torno da consulta ginecológica apontada pelas nossas participantes, independentemente se lésbicas ou mulheres bissexuais, foi a postura pouco receptiva do profissional, seja ele da rede particular seja da rede pública de saúde. Para Naira, Luiza e Lia, por exemplo, havia temas importantes como cólicas menstruais, preocupação com endometriose e cistos no ovário, respectivamente, mas que, diante da pouca abertura ao diálogo, deixavam de apresentar.

Apesar de não ter sido um objetivo do estudo, chamou-nos atenção a recomendação exacerbada de uso de anticoncepcional, mesmo naquelas situações de não pertinência enquanto método para evitar gravidez. Foi esta a situação experienciada por Naira:

Eu saí de lá com receita de anticoncepcional e daquele anel que coloca. Ela não me perguntou nada [sobre prática sexual], só deduziu, então deixei a dedução dela. Ela chegou falando e impondo, então deixei ela falar. Não tomei o anticoncepcional, nem fiz nada.

E ela se justificou do porquê recomendar o anticoncepcional para você?

Para eu não engravidar! (Naira, 19 anos, lésbica, branca)

Em síntese, tal recomendação reiterada é produto de consultas de ginecologia prioritariamente orientadas para as questões de reprodução, fazendo com que outros sintomas e queixas sobre saúde sexual fiquem em segundo plano:

A consulta ginecológica é muito voltada para o quer ou não quer engravidar. Ponto final. (Luiza, 28 anos, lésbica, negra)

Logo que eu entrei [na consulta] já falei que era lésbica, aí ele nem deu atenção. Tipo "ah tá, ela nãovai engravidar, não quer ter filho, pronto". Parecia que não tinha mais sentido eu estar ali. (Karen, 26, lésbica, branca)

Tais dados são pertinentes à argumentação de Barbosa e Facchini (2009) para o fato de que, por ter como porta de entrada para as consultas ginecológicas o início da vida (hetero)sexual ou a maternidade, as relações estabelecidas pelos médicos com as mulheres são operadas pela lógica das questões reprodutivas (Moscheta; Fébole; Anzolin, 2016) e a partir da naturalização da heterossexualidade (Lionço, 2008). Consequentemente, a saúde sexual é pouco abordada e parece haver pouco conhecimento dos médicos com relação ao sexo lésbico; as dúvidas quanto às infecções 
sexualmente transmissíveis (IST) não são esclarecidas e, na maioria das vezes, nem são abordadas durante a consulta. Nossas participantes relataram que sentiram falta de informações concisas quanto aos métodos de proteção disponíveis, bem como sobre as maneiras de transmissão de doenças frequentes ou que requerem mais preocupação:

DST [doença sexualmente transmissível] é algo que me preocupo, pedi informações no médico quando fui, mas não consegui. (Lara, 21 anos, lésbica, branca)

A última médica que fui me perguntou se usava alguma coisa. Eu disse que não, ela sugeriu a dedeira, mas nem eles sabem. $́$ complicado. (Luiza, 28 anos, lésbica, negra)

Os resultados desta pesquisa são semelhantes aos apontados em estudo de Rodrigues (2011), em que o tema da prevenção às IST entre lésbicas foi central. Estar em relacionamento estável e o entendimento de que práticas sexuais entre lésbicas são naturalmente mais seguras contribuíram para que o tema da prevenção adquirisse menor relevância (Rodrigues, 2011; Barbosa; Facchini, 2009).

As concepções de gênero atravessam o terreno da sexualidade, conferindo valores e comportamento diferentes à sexualidade masculina e feminina. Vale ressaltar que, entre as participantes do nosso estudo, a dificuldade em conversar sobre métodos de proteção contra as IST durante atendimento ginecológico esbarrou na percepção de que o profissional desconhece as práticas sexuais que mulheres lésbicas e bissexuais realizam. Ressalta-se novamente o "discurso do não saber" (Paulino; Rasera; Teixeira, 2019), no qual o não ter informações serve para isentar o médico de suas responsabilidades e do compromisso ético diante da pessoa que busca por cuidados.

\section{Considerações finais}

Os contextos dos atendimentos em ginecologia foram tomados neste estudo como espaço privilegiado para a análise das percepções das lésbicas e mulheres bissexuais acerca da relação entre médico e paciente e do cuidado à saúde, especialmente em termos de saúde sexual. As narrativas das mulheres sobre percepções e experiências em diferentes serviços de saúde (hospital, unidade básica de saúde, consultas em consultórios privados) demonstram claramente que as consultas ginecológicas se constituem em espaços sociais que restringem os direitos sexuais de mulheres lésbicas e bissexuais.

Performances e identidade de gênero atravessam as relações que as mulheres estabelecem com os ginecologistas no contexto dos atendimentos, ora (in) visibilizando a afirmação da orientação sexual e das práticas sexuais com mulheres, especialmente entre as bissexuais, ora conformando necessidade efetiva de revelação e afirmação de suas vivências afetivo-sexuais.

As dificuldades e as barreiras para a revelação da orientação sexual, antevista e experimentada em diferentes situações ao longo da vida pelas participantes do estudo, acarretam idas menos frequentes ao ginecologista ou falta de regularidade na busca por atendimento. Os obstáculos enfrentados para revelar a orientação sexual e, ainda mais grave, o não reconhecimento de sua prática sexual como legítima por parte dos médicos são achados importantes do estudo, corroborados pela revisão da literatura nos poucos estudos nacionais e internacionais disponíveis.

Situações de preconceito e discriminação após a revelação da orientação sexual se mostraram decisivas para o entrave de um atendimento integral e humanizado, acarretando descrédito, por parte das mulheres, do espaço da consulta ginecológica como atinente ao cuidado efetivo da saúde e, em última instância, revelando situações de violência institucional a que podem estar submetidas. Além disso, o não recebimento de informações pertinentes durante a consulta médica ou o não encaminhamento para realização de exames reforçam algumas suposições equivocadas dos profissionais (por exemplo, de que o sexo entre mulheres é naturalmente mais seguro), demonstrando falta de preparo técnico para lidar com as demandas de mulheres lésbicas e bissexuais.

Partindo de pressupostos defendidos no campo dos direitos sexuais, questionamos o quanto os espaços de atendimento ginecológico têm operado de forma bastante negativa, obstaculizando a inclusão da diversidade de mulheres lésbicas e operando na produção de exclusões e invisibilidades, na medida em que se reiteram padrões heteronormativos 
em relação ao gênero, à orientação sexual e às práticas sexuais entre mulheres. Assim, num contexto de ampliação da visibilidade de mulheres lésbicas e bissexuais, reforçamos a importância do reconhecimento de seus direitos à saúde sexual e, ao mesmo tempo, o cuidado humanizado e integral.

\section{Referências}

AARON, D. J. et al. Behavioral risk factors for disease and preventive health practices among lesbians. American Journal of Public Health, Washington, DC, v. 91, n. 6, p. 972-975, 2001.

AQUINO, L. O. R. Discurso lésbico e construção de gêneros. Horizontes Antropológicos, Porto Alegre, v. 1, n. 1, p. 79-94, 1995.

BAKER, K.; BEAGAN, B. Making assumptions, making spaces: an anthropological critique of cultural competency and its relevance to queer patients. Medical Anthropology Quarterly, Hoboken, v. 28, n. 4, p. 578-598, 2014.

BARBOSA, R. M.; FACCHINI, R. Acesso a cuidados relativos à saúde sexual entre mulheres que fazem sexo com mulheres em São Paulo, Brasil. Cadernos de Saúde Pública, Rio de Janeiro, v. 25, supl. 2, p. S291-S300, 2009.

BARBOSA, R. M.; KOYAMA, M. A. H. Mulheres que fazem sexo com mulheres: algumas estimativas para o Brasil. Cadernos de Saúde Pública, Rio de Janeiro, v. 22, n. 7, p. 1511-1514, 2006.

BATISTA, M. Hermenêutica filosófica e o debate Gadamer-Habermas. Crítica e Sociedade, Uberlândia, v. 2, n. 1, p. 101-118, 2012.

BJORKMAN, M.; MALTERUD, K. Lesbian women's experiences with health care: A qualitative study. Scandinavian Journal of Primary Health Care, Abingdon, v. 27, n. 4, p. 238-243, 2009.

BORRILLO, D. Homofobia: história e crítica de um preconceito. Belo Horizonte: Autêntica, 2010.

BRASIL. Ministério da Saúde. Política Nacional de Atenção à Saúde Integral da Mulher: princípios e diretrizes. Brasília, DF, 2003.

BRASIL. Ministério da Saúde. Política Nacional de Atenção Integral à Saúde de Lésbicas, Gays,
Bissexuais, Travestis e Transexuais. Brasília, DF, 2010.

BROWN, J. L. et al. Gynecological care among lesbians and bisexual women: notes on the situation in Argentina. Interface, Botucatu, v. 18, n. 51, p. 673-684, 2014.

BUTLER, J. Problemas de gênero: feminismo e subversão da identidade. Rio de Janeiro: Civilização Brasileira, 2003.

CARRARA, S. Moralidades, racionalidades e políticas sexuais no Brasil contemporâneo. Mana, Rio de Janeiro, v. 21, n. 2, p. 323-345, 2015.

COSTA, J. F. A construção cultural da diferença entre os sexos. In: CAMARGO, A. M. F.; GUIMARÃES, I. R. F.; SILVA, R. C. (Coord.). Coletânea de trabalhos desenvolvidos no VII Encontro de Orientação Sexual. Campinas: Unicamp, 1996. p. 3-12.

DAVIS, V. J. Lesbian health. Obstetrician \& Gynecologist, Hoboken, v. 7, p. 98-102, 2005.

DE OLIVEIRA, J. M.; ALMEIDA, M. J.; NOGUEIRA, C. Exploring medical personnel's discourses on the sexual health of lesbian and bisexual women in Greater Lisbon, Portugal. Revista Colombiana de Psicología, Bogotá, DC, v. 23, n. 2, p. 297-309, 2014.

DENENBERG, R. Report on lesbian health. Womens Health Issues, New York, v. 5, n. 2, p. 81-91, 1995.

DIAMANT, A. L.; SCHUSTER, M. A.; LEVER, J. Receipt of preventive health care services by lesbians. American Journal of Preventive Medicine, Amsterdam, v. 19, n. 3, p. 141-148, 2000.

DIAMANT, A. L. et al. Health behaviors, health status, and access to and use of health care: a population-based study of lesbian, bisexual and heterosexual women. Archives of Family Medicine, Chicago, v. 9, n. 10, p. 1043-1051, 2000.

FONTANELLA, B. J.; RICAS, J.; TURATO, E. R. Amostragem por saturação em pesquisas qualitativas em saúde: contribuições teóricas. Cadernos de Saúde Pública, Rio de Janeiro, v. 24, n. 1, p. 17-27, 2008.

GOFFMAN, E. Estigma: notas sobre manipulação da identidade deteriorada. Rio de Janeiro: Jorge Zahar, 1982.

GUIMARÃES, C. D. O homossexual visto por entendidos. Rio de Janeiro: Garamond, 2004. 
HEILBORN, M. L. Dois é par: gênero e identidade sexual no contexto igualitário. Rio de Janeiro: Garamond, 2004.

JOHNSON, M. J.; NEMETH, L. S. Addressing health disparities of lesbian and bisexual women: a grounded theory studies. Womens Health Issues, New York, v. 24, n. 6, p. 635-640, 2014.

LIONÇO, T. Que direito à saúde para população GLBT? Considerando direitos humanos, sexuais e reprodutivos em busca da integralidade e da equidade. Saúde e Sociedade, São Paulo, v. 17, n. 2, p. 11-21, 2008.

MELO, A. P. L. "Mulher Mulher" e "Outras Mulheres": gênero e homossexualidade(s) no Programa de Saúde da Família. 2010. 15 o f. Dissertação (Mestrado em Saúde Coletiva)Instituto de Medicina Social, Universidade do Estado do Rio de Janeiro, Rio de Janeiro, 2010.

MOORE, H. Understanding sex and gender. In: INGOLD, T. (Ed.). Companion encyclopedia of antrophology. London: Routledge, 1997. p. 813-830. Tradução de Julio Assis Simões para uso didático.

MOSCHETA, M. S.; FÉBOLE, D. S.; ANZOLIN. B. Visibilidade seletiva: a influência da heterossexualidade compulsória nos cuidados em saúde de homens gays e mulheres lésbicas e bissexuais. Saúde \& Transformação Social, Florianópolis, v. 7, n. 3, p. 71-83, 2016.

MOULIN, A. M. O corpo diante da medicina. In: Corbin, A.; Courtine, J.J.; Vigarello, G. (Coord.). História do corpo: as mutações do olhar: o século XX. Petrópolis: Vozes, 2009. v. 3. p. 15-82.

PARKER, R.; AGGLETON, P. HIV and Aids-related stigma and discrimination: a conceptual framework and implicatons for action. Social Science \& Medicine, Amsterdam, v. 57, n. 1, p. 13-24, 2003.

PARKER, R. Beneath the Equator: cultures of desires, male homosexuality, and emerging gay communities in Brazil. New York: Routledge, 1999.

PAULINO, D. B.; RASERA, E. F.; TEIXEIRA, F. B. Discursos sobre o cuidado em saúde de Lésbicas, Gays, Bissexuais, Travestis, Transexuais (LGBT) entre médicas(os) da Estratégia Saúde da Família. Interface, Botucatu, v. 23, p. 1-15, 2019.
PINTO, V. M. Aspectos epidemiológicos das doenças sexualmente transmissíveis em mulheres que fazem sexo com mulheres. 2004. $121 \mathrm{f}$. Dissertação (Mestrado em Saúde Pública)Faculdade de Saúde Pública, Universidade de São Paulo, São Paulo, 2004.

RAIMONDI, G. A. et al. Corpos (não) controlados: efeitos dos discursos sobre sexualidades em uma escola médica brasileira. Revista Brasileira de Educação Médica, v. 43, n. 3, p. 16-26, 2019.

RODRIGUES, J. L. Estereótipos de gênero e o cuidado em saúde sexual de mulheres lésbicas e bissexuais. 2011. 256 f. Dissertação (Mestrado em Saúde Pública)-Faculdade de Saúde Pública, Universidade de São Paulo, São Paulo, 2011.

RUBIN, G. S. The traffic in women: notes on the “political economy” of sex. In: Reiter, R. (Ed.). Toward an anthropology of women. New York: Monthly Review Press, 1975. p. 157-210.

STRAUSS, A.; CORBIN, J. Pesquisa qualitativa: técnicas e procedimentos para o desenvolvimento de teoria fundamentada. Porto Alegre: Artmed, 2008.

VANCE, C. A antropologia redescobre a sexualidade: um comentário teórico. Physis Revista de Saúde Coletiva, Rio de Janeiro, v. 5, n. 1, p. 7-31, 1991.

VILLELA, W.V.; ARILHA, M. Sexualidade, gênero e direitos sexuais e reprodutivos. In: BERQUÓ, E. (Org.). Sexo \& Vida: panorama da saúde reprodutiva no Brasil. Campinas: Editora da Unicamp, 2003. p. 85-150.

WEEKS, J. O corpo e a sexualidade. In: LOURO, G. C. (Org.) O corpo educado: pedagogias da sexualidade. Belo Horizonte: Autêntica, 2010. p. 35-82.

\section{Contribuição dos autores}

Rodrigues realizou a pesquisa de doutorado "Lésbicas e mulheres bissexuais: uma leitura interseccional do cuidado à saúde", da qual este artigo deriva. Elaborou o roteiro de entrevista, realizou as atividades de campo, analisou o material empírico e redigiu a tese e este artigo. Falcão orientou a pesquisa de doutorado de Rodrigues, apoiando o desenvolvimento de todo o trabalho. Contribuiu com as ferramentas teórico-metodológicas tanto para o trabalho de campo quanto para a análise do material empírico e apoiou a redação deste artigo.

Recebido: 22/02/2019

Reapresentado: 10/08/2020

Aprovado: 06/10/2020 